Japan. J. Med. Sci. Biol., 21, 41-46, 1968

\title{
INDUCTION OF TUBERCULIN HYPERSENSITIVITY IN GUINEA PIG EMBRYOS
}

\author{
TAKESHI YOSHIDA \\ Department of Tuberculosis, National Institute of Health, Tokyo
}

(Reseived : September 22nd, 1967)

\begin{abstract}
SUMMARY : It was investigated whether tuberculin hypersensitivity could be induced in guinea pig embryos. Two fetuses in each litter have been injected with heat-killed tubercle bacilli in liquid paraffin through the intact abdominal wall of the dams about 7 days prior to parturition. Forty injections in all were performed in 20 dams. Eight out of 49 youngs delivered by the dams, excluding 16 stillborns, gave rise to positive tuberculin reactions at birth. Positive reactors increased to 20 animals when all the live young were skin-tested about 2 weeks after birth. The hemagglutinating antibody was also detected according to the Middlebrook-Dubos's method in all sera taken from 15 animals which showed the positive skin reaction, although the titers varied widely. These findings indicate that guinea pig embryos about 7 days before birth already have the capacity to produce both cellular and humoral antibodies.
\end{abstract}

\section{INTRODUCTION}

For the present only a few reports are available about the induction of the delayed type hypersensitivity in guinea pig embryos. Weiss (1958) injected guinea pigs with tubercle bacilli during fetal life and elicited tuberculin reactions in some of these animals several weeks after birth. In those experiments, however, it is likely that guinea pig embryos injected with tubercle bacilli in utero became tuberculin sensitive for the first time at several days after birth, for positive skin reactions were observed 8 weeks after birth. Be that it may be, the capacity of fetal guinea pigs to develop the delayed hypersensitivity should be checked earlier by other experimental systems.

Uhr (1960) injected guinea pig embryos with several protein antigens in complete Freund's adjuvant and as a result delayed skin reactions to protein antigens were elicited in 31 out of 83 guinea pigs on the first day of life. He did not report about tuberculin reactions in them despite the use of complete adjuvant containing mycobacteria in the sensitizing antigen.

In the previous paper the author (Yoshida, 1967) described that neonatal guinea pigs could be sensitized to tuberculin by the injection of tubercle bacilli in liquid paraffin as rapid as could adult animals that is within 7 days.

This communication reports whether tuberculin sensitivity can be induced actively in guinea pig embryos as fast as newborn or adult animals.

MATERIALS AND METHODS

1) Method for the determination of parturition: Mating was made as described

吉田 彪 (国立予防衛生研究所結核部) 
in the previous paper (Yoshida, 1967). The pregnant guinea pigs were segregated individually and parturition date was determined by the method developed by Phillips et al. (1959). This technique is based on the estimation of the diastasis of the pubic bone epiphysis. The pubic spread could be estimated by feeling the position of the pubic bones with fingers of the right hand while supporting the animals with the left hand. According to our observations, the pubic bones have separated a distance of approximately $10 \mathrm{~mm}$ one week prior parturition, when the guinea pig embryos were injected with tubercle bacilli in liquid paraffin. Most fetuses diagnosed in this fashion to have been delivered a week later were actually born between 5 and 10 days after the injection.

2) Procedures of the sensitizing injections: Anesthesia of the gravid guinea pig was introduced and maintained by dropping anesthetic ether on defatted cotton wrapping gently around the head. The fetuses were injected through the intact abdominal and uterine walls. The injections always aimed at the muscle of the thigh or back of the embryo which was held between the operator's fingers. Four milligrams of heat-killed human type tubercle bacilli (Aoyama B strain) contained in $0.1 \mathrm{ml}$ of liquid paraffin were injected into an embryo. The injections were performed in only two fetuses in each litter since more injections greatly increased the rate of abortion.

It took about 3 minutes from the induction of anesthesia to the end of the injection. It was impossible to ascertain after birth which animals of a litter had been injected in utero despite the inclusion of Evans blue dye in the sensitizing suspension in several experiments.

3) Tuberculin skin reaction and detection of humoralantibody: Newborn animals were skin-tested usually on the first day of life with $20 \mu \mathrm{g}$ PPD. If the sensitizing injection had been administrated less than 7 days before birth, the skin test was postponed until 7 days after the sensitization. Those animals which did not show the sensitivity to tuberculin at that time were skin-tested again two weeks after birth.

Sera were taken from all animals two weeks after birth and hemagglutinating antibody was examined by modifications of Middlebrook-Dubos's method as described in the previous paper (Yoshida 1967).

Histology of the skin test sites was investigated as usual with the hematoxylin eosin stain.

\section{RESULTS}

The fate of the pregnant guinea pigs and their fetuses are recorded in Table 1. Twenty-three dams were subjected to the sensitizing injections after anesthesia, resulting in the abortion of three among them. Twenty dams gave birth to 69 young, of which $16(23.2 \%)$ were stillborn. The proportion of dead young among litters containing living animals was greater than that observed in our normal guinea pig colony and indicated that death of one or more fetuses did not cause abortion of the entire litter. In this event, it is likely that most of 16 stillborns among litters of living animals may have been killed by the injection of tubercle bacilli suspension in utero. If this supposition is valid, the number of living young which had been injected virtually in utero could be 24 since a total of 40 injections were attempted in 20 dams. Furthermore, 4 animals out of 53 living newborns died of failure in nursing; consequently, 49 animals were available in the present experiments.

Tuberculin skin reactions were tested at 7 days after the sensitization in utero. 
Table 1. Fate of pregnant guinea pigs and their fetuses

\begin{tabular}{lc}
\multicolumn{1}{c}{ No. of } \\
\hline Dams & 23 \\
Abortion & 3 \\
Deliveries which gave live young & 20 \\
Injections in utero & $2 \times 20=40$ \\
Delivered young & 69 \\
$\quad$ stillborn & 16 \\
$\quad$ liveborn & 53 \\
\hline
\end{tabular}

The maximum diameter of reactions was usually obtained at $24 \mathrm{hr}$ after the intracutaneous injection of $20 \mu \mathrm{g}$ PPD. Reactions equaling or exceeding $7 \mathrm{~mm}$ in diameter of redness were considered positive from the distribution of diameters of erythema elicited in neonatal guinea pigs as presented in Fig. 1. According to this criteria, 8 out of 49 newborns showed positive tuberculin reactions. As 40 injections had been performed in utero, $8 / 40(20 \%)$ is the rate of positive reactors among the animals tested. If the above mentioned hypothesis works, the positive rate reaches $8 / 24(33.3 \%)$.

Fig. 3 shows the microscopical appearance of the skin test site of the macroscopically positive reaction at $24 \mathrm{hr}$. Cell infiltration was remarkable in the sub-epidermal region and mononuclears were predominant around venules.

Thirty-one negative reactors have been skin tested again 2 weeks later. The distribution of diameter of erythema was shown in Fig. 2. Thus the reactions equaling or exceeding $10 \mathrm{~mm}$ in diameter were considered positive. On this base, additional 12 animals became tuberculin sensitive. Consequently, 20 animals in all gave rise to the positive tuberculin skin reactivity until 2 weeks after birth. On the other hand the

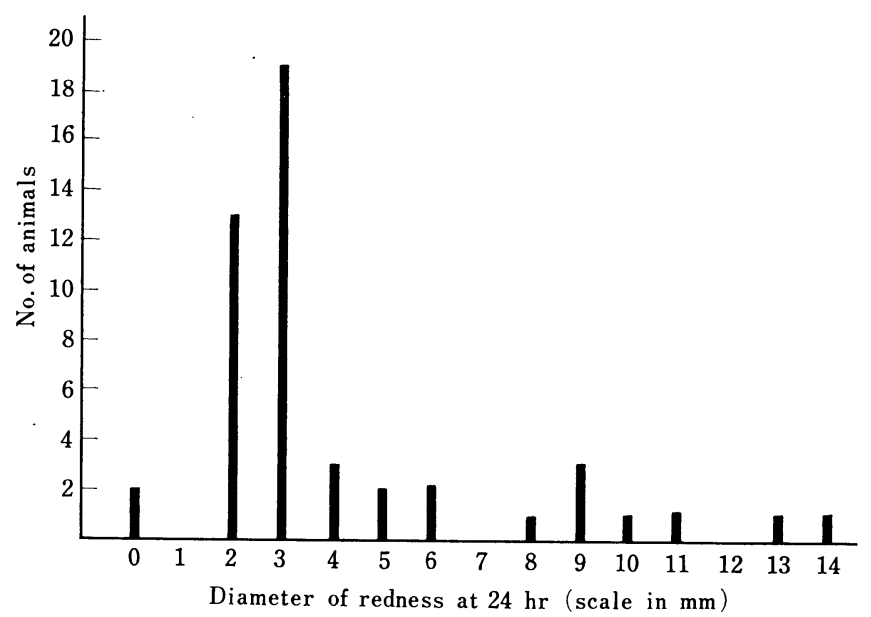

Fig. 1. Tuberculin reactions to $20 \mu \mathrm{g}$ PPD of guinea pigs injected in utero with $4 \mathrm{mg}$ of heat-killed tubercle bacilli in liquid paraffin. All guinea pigs were skin-tested 7 to 10 days after the sensitization in utero. 


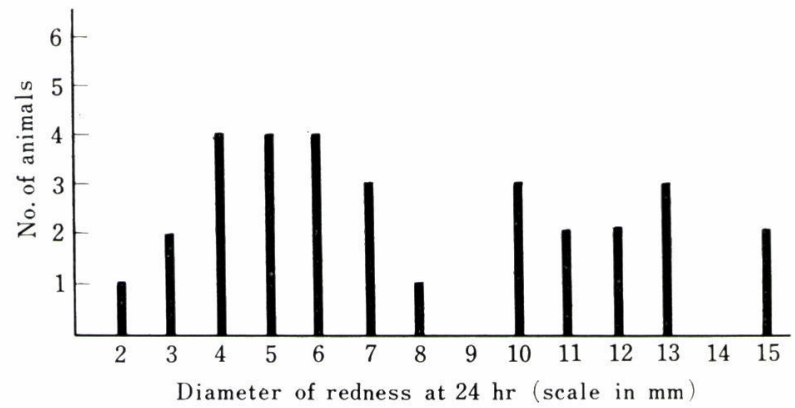

Fig. 2. Tuberculin reactions to $20 \mu \mathrm{g}$ PPD of guinea pigs 3 weeks after the injection in utero with $4 \mathrm{mg}$ of heat-killed tubercle bacilli in liquid paraffin. All animals tested here showed negative skin reactions to $20 \mu \mathrm{g}$ PPD 7 to 10 days after the sensitization in utero.

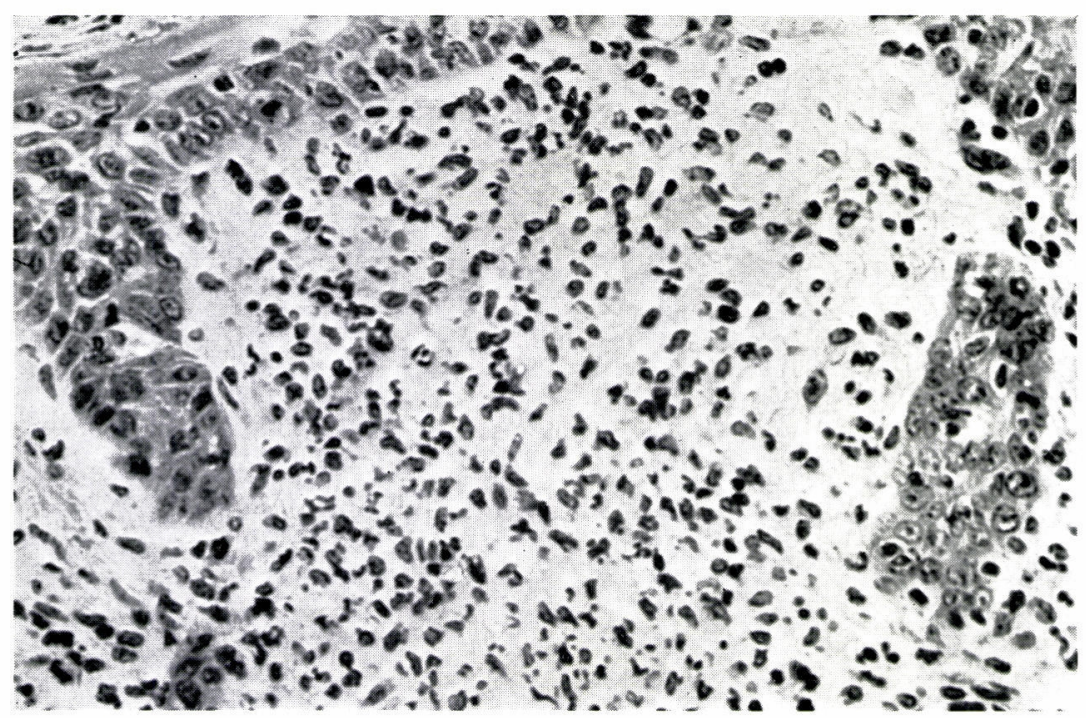

Fig. 3. Tuberculin skin test site at $24 \mathrm{hr}$ after the intracutaneous injection of $20 \mu \mathrm{g}$ PPD in guinea pigs sensitized in utero. Note diffuse cell infiltration consisting of mononuclears and leukocytes.

H. E. stain. $\times 400$

animals which were considered not to have been injected in utero also increased their skin reactivities at the retest with PPD because of the possible sensitization by the first injection of skin-testing antigen (PPD) at birth. The positive skin reactions observed at the retest, however, were significantly larger than those in guinea pigs sensitized actively with a single injection of skin-testing PPD as reported elsewhere (Yoshida and Hashimoto, 1966).

Data of these skin reactions are summarized in Table 2. Average diameters of erythema in the positive group at one and three weeks after sensitization were 10.4 and $12.1 \mathrm{~mm}$, respectively, and those in the negative group were 2.9 and $5.1 \mathrm{~mm}$, respectively.

Table 3 shows the positive skin reactions in two weeks old animals sensitized fetally, 
Table 2. Tuberculin reactions to $20 \mu \mathrm{g}$ PPD of guinea pigs injected in utero with $4 \mathrm{mg}$ of heat-killed tubercle bacilli in liquid paraffin

\begin{tabular}{ccccccc}
\hline \multirow{2}{*}{$\begin{array}{c}\text { Grouping of skin-tested } \\
\text { guinea pigs* }\end{array}$} & \multicolumn{2}{c}{$\begin{array}{c}\text { 1 week after the } \\
\text { sensitization }\end{array}$} & & \multicolumn{2}{c}{$\begin{array}{c}3 \text { weeks after the } \\
\text { sensitization }\end{array}$} \\
\cline { 2 - 3 } \cline { 5 - 6 } & $\begin{array}{c}\text { No. of } \\
\text { animals }\end{array}$ & $\begin{array}{c}\text { Average } \\
\text { diameter (mm) }\end{array}$ & & $\begin{array}{c}\text { No. of } \\
\text { animals** }\end{array}$ & $\begin{array}{c}\text { Average } \\
\text { diameter (mm) }\end{array}$ \\
\hline Positive Group & 8 & 10.4 & & 12 & 12.1 \\
Negative Group & 41 & 2.9 & & 19 & 5.1 \\
\hline
\end{tabular}

* guinea pigs were grouped on the basis obtained from the results shown in Fig. 1. and Fig. 2.

** these animals are from Negative Group at one week after sensitization.

Table 3. Tuberculin reactions and hemagglutination titers in guinea pigs at 3 weeks after the sensitization in utero

\begin{tabular}{ccc}
\hline G. P. No. & Diameter of skin reactions & $\begin{array}{c}\text { Heamagglutination } \\
\text { titers* }\end{array}$ \\
\hline 1 & $10 \times 10$ & 3 \\
2 & $10 \times 10$ & 1 \\
3 & $10 \times 11$ & 1 \\
4 & $10 \times 12$ & 1 \\
5 & $10 \times 12$ & 3 \\
6 & $11 \times 12$ & 4 \\
7 & $12 \times 12$ & 1 \\
8 & $12 \times 14$ & 3 \\
9 & $12 \times 14$ & 6 \\
10 & $12 \times 13$ & 5 \\
11 & $13 \times 14$ & 1 \\
12 & $13 \times 16$ & 5 \\
13 & $14 \times 15$ & 2 \\
14 & $15 \times 15$ & 1 \\
\hline
\end{tabular}

* hemagglutination titer in $\log _{2}$ of reciprocal of serum dilution.

in which circulating antibody estimation according to Middlebrook-Dubos's method was also available. All sera tested showed the circulating antibody activity in various degrees, although there were no correlation between the diameter of skin reactions and serum antibody titers.

\section{Discussion}

The present experiments about the tuberculin allergy in fetal guinea pigs confirmed in general the results reported by Uhr (1960) concerning the delayed hypersensitivity to protein antigens in such animals. Since the tuberculin hypersensitivity is considered as a typical model of the delayed type hypersensitivity, the present findings are regarded as a significant additional result to the report of Uhr (1960) in which he had not mentioned about tuberculin reactions in guinea pig embryos injected with protein antigens in complete Freund adjuvant containing mycobacteria.

As the author has already mentioned in the introduction, Weiss (1958) elicited tuberculin skin reactions in several guinea pigs 8 weeks old injected previously with 
living or dead BCG during fetal life. Since the investigator had not tested skin reaction earlier, there has remained a possibility that such animals may have developed tuberculin sensitivity not before but after birth responding to the antigenic stimuli of the remaining tubercle bacilli.

On the other hand, Rees and Garbutt (1961) reported the tuberculin shock induced by an intravenous challenge with tubercle bacilli in 4 week old mice vaccinated previously with BCG in utero and suggested the capability of the fetal animals to develop the delayed type hypersensitivity. In connection with the possibility mentioned above, " 4 weeks after sensitization" is too late to check the immunological ablility of the fetal animal and it is a prerequisite to observe the reactivity in young animals as early as possible.

These considerations led us to take the conditions under which one could test the skin reactivity in fetal or newborn guinea pigs as early as in adults, at least 5 to 7 days after the sensitization. Thus the author could elicite tuberculin reactions in the first day of life in guinea pigs sensitized in utero.

The present findings and the results obtained by Uhr (1960) permit us to conclude that the guinea pig embryo at least 7 days before delivery already has the capacity to develop the delayed type hypersensitivity.

\section{ACKNOWLEDGEMENT}

The author wishes to thank Dr. T. Hashimoto, Department of Tuberculosis for his useful discussions and advices, Dr. Y. Egashira, Chief of the Department of Pathology, N. I. H. Tokyo, for his histological findings, Dr. S. Yamamoto and Dr. T. Nakano, the Department of Veterinary Science for their advices of caring the gravid guinea pigs and Mr. S. Haga for his technical assistance.

\section{REFERENCES}

Phillips, B. P., Wolfe, P. A. And Gordon, H. A. (1959): Studies on rearing the guinea pig germfree. Ann. N. Y. Acad. Sci., 78, 183-207.

REES, R. J. W. AND GARBUTT, E. W. (1961): Development of immunity to tuberculosis in adult mice injected with tubercle bacilli during fetal life. Immunology, 4, 88-93.

UHR, J. W. (1960): Development of delayed-type hypersensitivity in guinea pig embryos. Nature, 187, 957-959

WEISS, D. W. (1958) : Inhibition of tuberculin skin hypersensitivity in guinea pigs by injection of tuberculin and intact tubercle bacilli during fetal life. J. Exptl. Med., 108, 83-104

YoshidA, T. (1967): Passive transfer of tuberculin hypersensitivity in newborn guinea pigs. Japan. J. Med. Sci. Biol., in press.

YoshidA, T. AND HAshimoto, T. (1966): Induction of delayed hypersensitivity in guinea pigs with old tuberculin or purified protein derivative. Japan. J. Med. Sci. Biol., 19, 259-262. 